\title{
Study on the selected engineering properties and sensory evaluation of tikur blended Chhana podo during infrared radiation assissted baking
}

\author{
- N. Sai Prasanna*, Ch. Someshwara Rao and B. Manjula \\ College of Agricultural Engineering (ANGRAU), Madakasira, Anantapur (A.P.) India \\ Email : sprasanna557@gmail.com; somesh027@gmail.com; manjulakrishna.08@gmail.com \\ *Author for Correspondence \\ Research chronicle : Received : 13.04.2018; Revised : 11.05.2018; Accepted : 19.05.2018
}

SUMMARY :

Chhana podo is a popular dairy product of the Indian sub-continent, prepared from cow milk standardized to 4 per cent fat and 8.5 per cent SNF. This energy rich product is commonly prepared by baking of Chhana, sugar, tikur, baking powder in ratio of 20:6:1:0.3 at temperature of $120^{\circ} \mathrm{C}-130^{\circ} \mathrm{C}$ with IR of 180-200 Volts. Curcuma angustifolia Roxb. (Tikur) is a low fat sweetner which reduces the risk of cardio-vascular diseases and diabetes. Addition of tikur to Chhana podo gives a brown crust with white or light brown inner body, moist crumb, moderately spongy cake like texture with a typical cooked flavour and rich taste. Baking time and temperature are two important process considerations influencing the heat and mass transfer, moisture content and product quality during baking. In this study the effect of IR on selected physico and textural characteristics of Chhana podo were studied at different combinations. The selected conditions for baking of Chhana podo $130^{\circ} \mathrm{C}$ and $200 \mathrm{~V}$ for $120 \mathrm{~min}$ with IR on at $60 \mathrm{~min}$. and the parameters viz., crumb and crust moisture contents and specific volume were determined as 22.74 per cent, 14.94 per cent and $1.23 \mathrm{~cm}^{3} / \mathrm{g}$, respectively. Textural attributes such as hardness, chewiness and gumminess increased with baking time and IR temperature while springiness, cohesiveness and resilience increased upto $80 \mathrm{~min}$ due to the filling-up of pores water and liquid by fat and expanding water, but decreased thereafter.

KEY WORDS : Chhana podo, Baking temperature, Moisture, Tikur, Effect of IR, Quality attribute

How to cite this paper: Prasanna, N. Sai, Rao, Ch. Someshwara and Manjula, B. (2018). Study on the selected engineering properties and sensory evaluation of tikur blended Chhana podo during infrared radiation assissted baking. Internat. J. Proc. \& Post Harvest Technol., 9 (1) : 1-9. DOI: 10.15740/HAS/IJPPHT/9.1/1-9. Copyright@ 2018: Hind Agri-Horticultural Society. 